\section{Design-Arte Brasileiro: reverberações e transgressões que provocam a imaginação no objeto}

Adriana Dornas ${ }^{(1)}$

Resumo: A partir de uma abordagem epistemológica sobre o Design-Arte, o artigo se propõe apresentar o Design-Arte brasileiro contemporâneo investigando o diálogo e as relações entre o design e a arte. O processo projetual proposto pelo Design-Arte cria novas formas de linguagem com a presença de uma profusão de signos. Este segmento de design apresenta uma natureza híbrida, pois pode-se perceber que hoje os designers incorporam critérios utilizados pela arte. Para tanto, opta-se pela análise do trabalho dos designers Juliana Vasconcellos e Matheus Barreto, que coloca em questão a hibridização e a ambiguidade de seus objetos. O trabalho desses designers traz uma questão sobre o caráter artístico agregado às peças com a produção em escalas reduzidas, únicas, com peças numeradas e assinadas. A partir desse raciocínio, o ponto central do artigo é refletir como o processo de experimentação do Design-Arteintegra as relações entre arte e design. A essência do texto é pensar o Design-Arte ligado às suas manifestações e experimentações propostas. Neste sentido, o artigo apresenta as peculiaridades e estratégias utilizadas pelos dois designers que confrontam a dimensão cotidiana do objeto.

Palavras-chave: Design - Design-Arte - Design Brasileiro - Design Contemporâneo.

[Resumos em espanhol e inglês nas páginas 79-80]

(1) Adriana Dornas. Visiting professor [UFMG - Universidade Federal de Minas Gerais, Brasil], GraduateProgram in Design, UP -Universidad de Palermo, Argentina. adrianadornasmoura@gmail.com, https://orcid.org/0000-0003-3810-983X

\title{
Introdução
}

Devir é um verbo tendo toda sua consistência; ele não se reduz, ele não nos conduz a "parecer", nem "ser", nem "equivaler", nem "produzir"

Deleuze 
Pode-se afirmar que a contemporaneidade vive em constante mutação que envolve aspectos sociais, políticos, econômicos, tecnológicos, ambientais, culturais, entre outros. $\mathrm{Na}$ narrativa contemporânea do mundo, o Design-Arte antecipa cenários e sedimenta universos semânticos que não se baseiam na cultura industrial. Tanto odesignquanto a arte apresentam a experiência e a dimensão cultural como protagonistas e ambos são reflexos de um contexto.

Pensar o design fora das possibilidades puramente industriais e analisá-lo sob a diluição de fronteiras redefine não somente o processo de produção, mas essa escolha disruptiva conduz areflexões e experiências que transcendem os limites impostos por essa produção industrial. Essa modalidade de design faz com que o processo projetual apresente uma ambiguidade nos objetos, complementado por um caráter artístico agregado a essas peças.

Com o hibridismo entre a arte e o design, pode-se perceber uma suposta linha divisória que se diluiinteiramente e a poética da liberdade de quem transita entre essas linhas. Isso fazcom que se estimule uma reflexão crítica sobre as peças. Nessa perspectiva, pode-se alegar que o design encontrou um terreno fecundo para criar objetos que sejam interpretados, ao menos em parte, como arte. Ademais, esses mesmos objetos são projetados para emocionar e tocar os sentimentos por meio de projetos em edições limitadas e assinadas. Nesse contexto o Design-Arte sintetiza a interseção da arte com o design, na qual nenhum conceito precisa ser rígido, e assim cria-se um campo de tensões e de inquietude onde os contornos são intencionalmente borrados. E nessa relação entre a arte e o design, deve-se pensar primeiramente a episte me dos campos, isto é, como podemos estudar a arte e como podemos estudar o design. A aproximação do design ao campo da arte, introduz no projeto questões referentes ao conhecimento sensível do mundo e a experiência estética por meio dos objetos. Portanto, quando o projeto e a experiência adentram o campo do design é para provocar relações.

\section{Design-Arte: pluralidade de relações e espectros}

A cultura do design brasileiro, com seus protagonistas recentes, nos faz questionar quais são os códigos escolhidos por eles e quais são as fronteiras transpostas. Em sintonia com a metamorfose da contemporaneidade, esses designers habitam territórios de constante investigação e, consequentemente, desenvolvem trabalhos experimentais.

A força da fusão da arte com o design aparece na mobilidade dessas fronteiras que se deslocam de seus lugares já estabelecidos, encontrando territórios que propõem novas interpretações e experiências no processo projetual. Essa questão é melhor exemplificada quando os designers dilatam e incorporam as atividades pertencentes ao mundo da arte. Canclini assegura: precisamos aprender como os métodos de hibridização se manifestam no mundo contemporâneo, com isso necessitamos entender os movimentos artísticos em conexão com os processos sociais, culturais, entre outros. Mais do que isso, temos que observar os novos papéis que estendem sua ação para além do que se organiza como campo artístico (Canclini, 2012; Canclini, 2003). 
Os objetos desenvolvidos por estes designers dizem respeito às metodologias e experiências contemporâneas do design no Brasil, que são seduzidas pela linguagem e significados dos objetos. Naylor e Ball (2005) definem a poética do design como uma categoria de prática de projeto que gera um acervo de artefatos experimentais que investigam, questionam e elucidam a cultura que os produziu. E os mesmos autores complementam:

Os objetos poéticos são vistos como projetos específicos constitutivos da cultura, operando dentro das tradições, costumes e socialidade de uma cultura, separados do produto, do mercado ou do design industrial; uma prática desenvolvida por designers, gerando uma classe de objetos situada no interstício entre design e arte (Naylor; Ball, 2005, p. 9, tradução nossa). ${ }^{1}$

A partir desse raciocínio, pode-se afirmar que séries limitadas de móveis ou peças únicas (one-off) conseguem deleitar colecionadores e marchands de museus e galerias. A ambiguidade destas peças instiga a discussão sobre questões da arte e do design. Portanto, o ato de sentar nessas peças híbridas não é primordial e não se finda nas relações ergonômicas e funcionais, mas sim, primordiais, são as sensações que elas despertam pela sua aproximação com a esfera da arte.

Arte e design se caracterizam pela atividade criadora e cabe aqui resgatar o pensamento de Flusser (2007) quando relata que nem sempre designer e artista foram indivíduos distintos na confecção e execução de seus trabalhos. Neste sentido, pode-se afirmar que a subjetividade do designer ou artista que, afinalé quem revela a essência dessa condição transversal, é a característica marcante no Design-Arte.

A cadeira Jacarandá foi confeccionada em 2017 para galeria Legado Arte de São Paulo, com design de Juliana Vasconcellos e Matheus Barreto, executada em peça única (oneoff) em madeira maciça, originária de uma porta de jacarandá antiga e tem assento em fios de algodão com dimensões $77 \mathrm{~cm} \mathrm{x} 50 \mathrm{~cm}$ x $136 \mathrm{~cm}$. É importante observar o uso de tal material, pois, essa madeira é rara, valiosa e é uma espécie que se enquadra no nível de vulnerabilidade, correndo riscos de extinção.

Nesse trabalho em especial, o conceito e a linguagem alcançam sofisticação pois a designer relata: "o conceito da cadeira tem uma ideia de ascensão espiritual, e tem uma conexão com o trono. Possuí uma geometria limpa, elaborada com encaixes" (VASCONCELOS, comunicação pessoal, 19 de março 2021). Eles conseguem idealizaruma peça (one-off) escultural, em que a exteriorização do gesto apresenta uma reflexão sobre o sentido do devir e revela os paradoxos vinculados a uma linguagem híbrida.

Pode-se afirmar que as peças one-off atingem um caráter cultural que transcendem o território entre a arte e o design e seguindo as questões propostas por Deleuze (1974), é plausível trazer o conceito filosófico do "devir" em que pode-se afirmar que a produção dos objetos, sob a égide do Design-Arte, assimila a ideia que nos leva ao acontecimento que nos permite vislumbrar a criação de diferentes territórios, que se abrem para criação de outros processos de subjetivação. Esse conceito de Deleuze foi aqui resgatado para pensar a originalidade e transformação das coisas sob outra perspectiva. Para Deleuze (1974) os corpos das coisas (objetos e demais seres vivos) são causas uns para os outros, 
logo, a relação que se estabelece entre esses sentidos são acontecimentos. Portanto, esses acontecimentos são compreendidos como "devir", que transmutam o nosso sentido, fazendo com que o projetar se torne um envolvimento mútuo e recíproco. Dessa forma, a produção do objeto de design apresenta esse devir.

Encontram-se na cadeira Jacarandá, em sua forma e volume, indícios de significados correspondentes à concepção mais voltada à arte. É uma peça maciça e robusta, mas ao mesmo tempo suave e delicada. Concebida num movimento contínuo, onde a junção do encosto vertical e a base da cadeira horizontal, por meio de encaixe, sustentam um assento de fios de algodão fluídos semelhantes a caules de plantas aquáticas. Tudo isso dá um caráter único e exclusivo à cadeira que retém uma elegância e sofisticação em sua linguagem.

O curador de design Bruno Simões afirma: "a meu ver essa categoria (one-off) se refere ao produto capaz de apresentar com clareza a visão de seu criador, com uma linguagem própria e com força suficientemente capaz de se expressar por meio de diferentes mídias, sempre mantendo a essência criativa do autor. O design autoral necessariamente precisa ser gerado por autores cuja trajetória e pensamento vão além da simples produção estilística" (Simões, 2019).

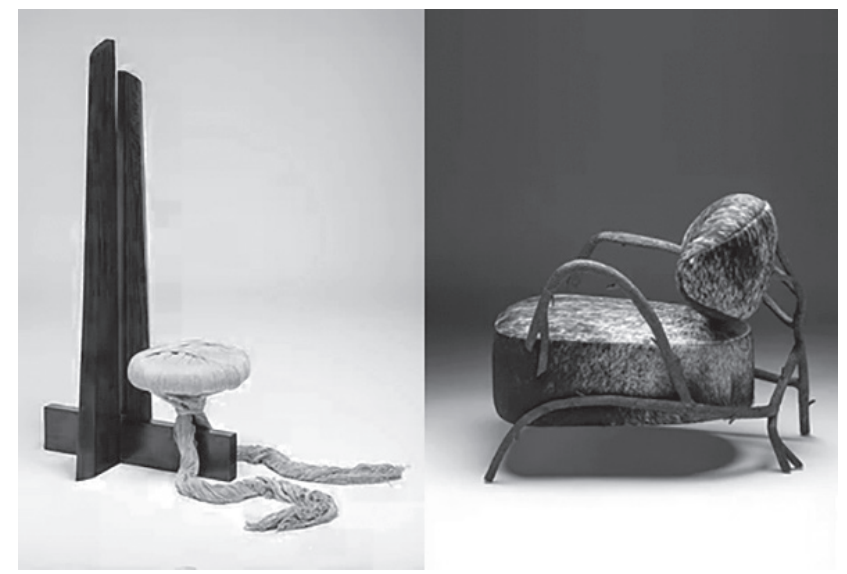

Figura 1. Cadeira Jacarandá e Cadeira Galho.

Fonte: https://www.julianavasconcellos.com/copia-jacaranda

A cadeira Galho possui estrutura em bronze patinado e estofamento em couro com dimensões $80 \mathrm{~cm}$ x $100 \mathrm{~cm}$ x $77 \mathrm{~cm}$, ela foi confeccionada em 2017 para Galeria Nilufar, de Milão. Seu contorno nos convida a tateá-la e nos oferece uma unidade que transmite a percepção douniverso natural, pois seu desenho se originou de um galho de uma árvore 
do cerrado ${ }^{2}$. A produção da cadeira combina processos tecnológicos e tradicionais, pois os designers parecem moldar essa cadeira à mão, tanto quanto os artesãos e artífices da antiguidade.

A peça possui uma coerência formal e representa a síntese que explora a diferença entre o absoluto e o relativo, numa disputa entre forma escultural e função poética. A percepção é de que a cadeira é um objeto-metáfora, isto é, ela representa os múltiplos aspectos da contemporaneidade, sob uma faceta que nos leva a um cenário de refúgio, caracterizado por novos significados e novas relações, surgidos e estimulados pela hibridização da arte com o design. O desenho é realçado pela escolha do material e o tratamento da superfície com texturas, que nos suscitam a imaginar que estamos sentados em uma árvore. A cadeira foi executada com tiragem de apenas oito peças, destinada, portanto, a um público de colecionadores, isto é, a cadeira é vendida como peça exclusiva de edição limitada, assinada e numerada.

A cadeira se torna um objeto enigmático, rica de signos, e nela se reconhece a propensão para o gesto artístico. O resultado é uma peça que explora a experimentação e a potencialidade do material, combinado a uma interpretação de significados. A fluidez dos pés da cadeira contrasta com a solidez do assento e do encosto dando à peça um reconhecimento de lugar de repouso e que usa o hibridismo entre a arte e o design para a transferência de significados que colocam constantemente as certezas em infinitas interrogações.

A semelhança e o parentesco do design com a arte é fecundo e os limites se confundem. Desse modo, o Design-Arte consegue criar uma realidade própria e elevar o design a uma coexistência com elementos da arte, que encontra seu lugar nos museus e galerias, em uma conciliação rizomática composta pelo polimorfismo. Mas é importante destacar que essa ambiguidade e essa multiplicidade do rizoma, não deslocam o objeto de design das suas funções utilitárias ou cotidianas, mas nitidamente, propõem uma indistinção, afirmando que o objeto pode assumir inúmeras funções.

Vial (2015) nos esclarece que independentemente de considerar uma obra como arte ou como design, o importante é a atitude de vanguarda e autenticidade em que se posiciona o designer ou o artista, entendendo aqui que os movimentos de vanguarda são sempre experimentais e exploratórios. O autor acrescenta que vanguarda é: "um movimento inovador, que rompe com a tradição e antecede os demais, dando um novo impulso ao desenvolvimento de uma ideia, de uma técnica, de uma arte"3 (Vial, 2015, p. 32). Portanto, o objetivo do Design-Arte não é somente produzir conhecimento e objetos, mas é sobretudo produzir cultura.

Juliana Vasconcellos e Matheus Barreto estão comprometidos com a experimentação e exploram a natureza e suas formas, mas também os sistemas dentro dos quais são criados e utilizados. Qualidade, desenho exclusivo, tecnologia, mas também acabamento artesanal, são características que distinguem o trabalho destes designers. A força da fusão da arte com o design aparece na busca de novas possibilidades e esse deslocamento provoca o espectador a sair do lugar comum, produzindo novas experiências sensoriais.

Argan (2005) afirma que o êxito almejado, tanto pelo artista quanto pelo designer ao desenvolver seus trabalhos, embora tenham enfoques distintos, deriva do uso de dispositivos tais como materiais disponíveis ou tecnologias mais complexas. $\mathrm{O}$ autor afirma: "essa subjetividade é expressa na arte por meio do objeto em quantidade mínima e de valor 
máximo. O valor do objeto artístico está diretamente ligado à escassez e ao refinamento" (Argan, 2005, p. 252). Com isso o trabalho experimental que os designers desenvolvem permite a criação e confecção de peças assinadas, peças únicas e/ou pequenas séries e cria-se um significativo diálogo entre a arte e o design.

\section{Considerações Finais}

Entende-se, portanto, que o hibridismo entre a arte e o design se manifesta de diversas formas e produzindo deslocamentos e rupturas, peças em edição limitada e assinadas que possuem uma concepção mais voltada à arte e são expostas em museus e galerias. A partir desse raciocínio, pode-se afirmar que as cadeiras desenvolvidas por Juliana Vasconcellos e Matheus Barreto habitam um universo múltiplo e rizomático, que transita sem embaraços entre a arte e o design, dessa forma suas peças conseguem satisfazer colecionadores, marchands e vários atores envolvidos no sistema do Design-Arte.

Pode-se reconhecer que o Design-Arte é uma vertente do design na qual o designer faz experimentações, sejam materiais, conceituais ou estéticas. Nesse caso, pode-se perceber como esses designers se enquadram no âmbito do Design-Arte, mantendo um grau de autonomia e criando suas próprias instâncias, valores e princípios de projetação. A produção destes designers mostra a diluição das fronteiras entre várias linguagense com essas fronteiras diluídas, não é mais possível definir tão claramente onde acaba o design e onde começa a arte, e é isso que torna o trabalho deles tão significativo. Peças concebidas dentro dessa categoria demonstram com clareza a visão do designer, com uma linguagem própria capaz de expressar a essência criativa do autor, atingindo muitas vezes um caráter culturale o resultado é um exercício onde são obtidos resultados impactantes.

Dessa maneira em nossa contemporaneidade, vivemos diversas consequências da aproximação do design com a arte, porque o design contemporâneo assim como a arte contemporânea devem ser pensados enquanto ruptura de paradigmas. Como tal é necessário avaliar processos, mediações, os conceitos, as teorias e as dinâmicas do espaço social. Pois lidamos com sistemas complexos: rizomas. Deste modo quando a experiência adentra o campo do design é para provocar relações.

\section{Notas}

1. "Poetic objects are seen as specific designs constitutive of culture, operating within the traditions, customs and sociality of a culture, set apart from product, market or industrial design; a practice developed by designer-makers, generating a class of objects situated in the interstice between design and art".

2. O cerrado é um bioma extenso, que se localiza na região central do Brasil.

3. Un mouvementnovateur, qui rompt avec la tradition et devance les autres, endonnantune impulsion nouvelle au développementd 'une idée, dùne technique, d'un arte. (Vial, 2015, p.32)(Tradução Livre) 


\section{Referências}

Argan, Giulio Carlo. (2005). História da arte como história da cidade. Martins Fontes. Canclini, Nestor. (2003). Culturas Híbridas: Estratégias para entrar e sair da Modernidade. Tradução, Heloíza Pezza Cintrão, Ana Regina Lessa. (4º ed.). Editora da Universidade de São Paulo.

Canclini, Nestor. (2012). A sociedade sem Relato: Antropologia e Estética da Iminência; tradução, Maria Paula Gurgel Ribeiro. Editora da Universidade de São Paulo.

Deleuze, Gilles. (1974). Lógica do Sentido. Perspectiva.

Flusser, Villém. (2007). O mundo codificado: por uma filosofia do design e da comunicação. CosacNaify.

Naylor, Maxime; Ball, Ralph. (2005). Form follows idea: an introduction to design poetics. BlackDog.

Simões, Bruno. Entrevista. [mensagem pessoal]. Mensagem recebida por: adrianadornasmoura@gmail.com. Belo Horizonte, 04 fev. 2019.

Vasconcelos, Juliana. https://julianavasconcellos.com/designs/

Vial, Stéphane. Qu’est-ce que larechercheen Design? Sciencesdu Design, Paris, p. 22-36, 2015. https://www.cairn.info/revue-sciences-du-design-2015-1-page-22.htm.

Resumen: Basado en un enfoque epistemológico del Diseño-Arte, el artículo propone presentar el Diseño-Arte brasileño contemporáneo investigando el diálogo y las relaciones entre diseño y arte. El proceso de diseño propuesto por Design-Arte crea nuevas formas de lenguaje con la presencia de una profusión de signos. Este segmento del diseño tiene un carácter híbrido, como se puede apreciar que hoy los diseñadores incorporan criterios utilizados por el arte. Para ello, opta por el análisis del trabajo de los diseñadores Juliana Vasconcellos y Matheus Barreto, que cuestiona la hibridación y ambigüedad de sus objetos. El trabajo de estos diseñadores plantea una pregunta sobre el carácter artístico que se agrega a las piezas numeradas y firmadas o únicas a pequeña escala. A partir de este razonamiento, el punto central del artículo es reflexionar sobre cómo el proceso de experimentación diseño-arte integra las relaciones entre arte y diseño. La esencia del texto es pensar en el Diseño-Arte vinculado a sus manifestaciones y experimentos propuestos. En este sentido, el artículo presenta las peculiaridades y estrategias utilizadas por los dos diseñadores que afrontan la dimensión cotidiana del objeto.

Palabras clave: Diseño - Diseño-Arte - Diseño Brasileño - Diseño Contemporáneo.

Abstract: Based on an epistemological approach to Design-Art, this article aims to present contemporary Brazilian Design-Art by investigates the dialogue and relations between design and art. The project process proposed by Design-Art creates new forms of language with a profusion of signs. This design segment has a hybrid nature, as it can be seen that designers incorporate criteria used by art. To this end, we chose to analyze the 
work of designers Juliana Vasconcellos and Matheus Barreto, which calls into question the hybridization and ambiguity of their objects. The work of these designers raises a question about the artistic character added to small scale production of numbered and signed or unique pieces. Based on this reasoning, the central point of the article is to reflect on how the design-art experimentation process integrates the relations between art and design. The essence of the text is to think of Design-Art linked to its proposed manifestations and experiments. In this sense, the article presents the peculiarities and strategies used by the two designers who confront the daily dimension of the object.

Keywords: Design - Design-Art - Brasilian Design - Contemporary Design.

[Las traducciones de los abstracts fueron supervisadas por el autor de cada artículo] 